\title{
A parent's perspective of the bidirectional impact of mental illness in families
}

\author{
Michael Frederick Naughton*1, Darryl Maybery ${ }^{1}$, Melinda Goodyear ${ }^{1,2}$ \\ ${ }^{1}$ Monash University, School of Rural Health, Australia \\ ${ }^{2}$ The Parenting Research Centre, Australia
}

Received: July 1, 2018

DOI: $10.5430 /$ cns.v7n1p46
Accepted: September 7, $2018 \quad$ Online Published: September 17, 2018

URL: https://doi.org/10.5430/cns.v7n1p46

\begin{abstract}
Objective: Recent research has found over $70 \%$ of children attending a mental health service also have a parent with a mental illness. Research on the impact of mental illness in families focuses primarily on how parental mental illness impacts on children. What is not understood is the experience of parents and children where both have a mental illness. The aim of this study was to investigate the experiences of parents where both a child and a parent have a mental illness.

Methods: Thirty-seven parents were interviewed using a narrative design to determine their personal and family experiences. Interviews were analyzed using interpretative phenomenological analysis with a number of themes highlighted.

Results: Themes particular to this family type were: impact of parental mental illness; specific strategies; bidirectional impacts of mental illness; and intergenerational factors. Also raised were supports parents would have liked. From the narrative of these parents the challenges of families, where both a parent and a child have a mental illness, are highlighted.

Conclusions: It is from these interviews, that awareness of clinicians can be raised, and more effective, well-thought-out interventions put in place. Interventions that take account of the bidirectional influences of mental illness will be more successful in meeting the needs of all members of a family. People do not operate in isolation and providing a family focused approach is an essential first step in helping people manage where mental illness is a prevalent factor for different family members.
\end{abstract}

Key Words: Family, Parent, Child, Mental illness, Bidirectional impact

\section{INTRODUCTION}

Many studies consider the unidirectional impact of mental illness with a lot known about the role of endogenous and exogenous risk factors in the development of mental illness. ${ }^{[1]}$ This knowledge stems from research that indicates children are at "high-risk" for developing psychopathology, ${ }^{[2]}$ particularly with a genesis in the family. Walker and Diforio ${ }^{[3]}$ highlight prenatal environmental factors as influencing fetal development. Halmoy et al. ${ }^{[4]}$ and Badcock and Crespi ${ }^{[5]}$ suggest parental genes are determining factors for the development of children's mental illness. The genetic component though, is a part of a much larger picture of environmental and social influences.

The number of children of parents with a mental illness developing mental illness themselves cannot be underestimated. The van Santvoort et al. ${ }^{[6]}$ systematic review of 76 papers found a strong relationship between parental disorders and various childhood disorders. A recent review of nine studies of adult psychiatric services found parent numbers amongst service users ranging from 12.2 to 45.0 percent. ${ }^{[7]}$ Leijdesdorff et al. ${ }^{[1]}$ proposed children of parents with a mental illness have a 50 percent chance of developing mental illness

\footnotetext{
${ }^{*}$ Correspondence: Michael Frederick Naughton; Email: michael.naughton@monash.edu; Address: Monash University, School of Rural Health, Australia.
} 
themselves. Göpfert, et al. ${ }^{[8]}$ and Maybery and Reupert ${ }^{[9]}$ found parental mental illness could adversely affect parent and child well-being. These children may not develop mental illness, ${ }^{[10]}$ but there is an increased risk ${ }^{[11,12]}$ with some authors suggesting children of parents with a mental illness are more likely to have greater difficulties in all aspects of their life. ${ }^{[13,14]}$

Where parental mental health improves the literature indicates improvements in children's attachment, temperament and cognition. ${ }^{[15]}$ Falkov $^{[16]}$ emphasizes a connection between biological and psychosocial factors in the development of children's mental health. Vondrova et al. ${ }^{[17]}$ in their study of 87 children, found exogenous determinants significantly affecting children's mental health.

Childhood disability and developmental disorders impact on family systems. Effects on parenting, marriage, work and caring are well known ${ }^{[18]}$ with Hayes and Watson ${ }^{[19]}$ finding childhood Autism causing more stress than any other disability. Kuusikko-Gauffin et al. ${ }^{[20]}$ found high anxiety in parents of children with a disability. Manuel, et al. ${ }^{[21]}$ found that mothers of children with a physical disability were at increased risk of depression. In contrast literature on the impact of children's mental illness on parent's is limited.

A unidirectional view of mental illness provides a constricted view of what happens in families where a parent and child have a mental illness. Gudmundsson and Tomasson ${ }^{[22]}$ and Busch and Barry ${ }^{[23]}$ found caring for a child with a mental illness affects caring and psychological health of care givers more than any other condition. Mensah and Kiernan ${ }^{[24]}$ found a number of deficits in children whose parent had a mental illness whilst Radke-Yarrow and Klimes-Dougan ${ }^{[25]}$ comment on the importance of the relation between parental and child mental illness.

Jessop and De Bondt ${ }^{[26]}$ determined $29.6 \%$ of parents whose children attended a child mental health service identified as having a mental illness. Similarly Gatsou et al. ${ }^{[27]}$ found 59 percent and in a Netherlands child and youth service an estimated 42.1 percent of mothers and 21.8 percent of fathers had a mental illness. ${ }^{[28]}$ The two highest CAMHS appraisals of co-existing parental mental illness have been Naughton et al. ${ }^{[29]}$ with 79 percent and Baker and Lees ${ }^{[30]}$ with 70 percent. This data indicates dual parent-child disorders as being a very important public health issue.

Gladstone ${ }^{[31]}$ hypothesized about impacts on parents of childhood mental illness whilst Maybery et al. ${ }^{[13]}$ report an influence on children of parental mental illness. The Falkov ${ }^{[16]}$ Family Model of the interplay between risk and resilience offers a useful overview of the link between bio-genetic inheritance and psychosocial adversity in families where there is co-existing mental illness. His model shows the variety of connections existing in families and how these impact across generations. Taking the ideas of this interplay a step further this study aimed to investigate, through in-depth interviews, the interplay of factors for parents and children where both have a mental illness.

\section{Methods}

Community mental health clinicians were asked to identify potential families for the study. The criterion for inclusion was a parent and a child from the same family both with a mental illness, with children needing to be over the age of 12 years. Clinicians spoke to eligible parents about the study and provided information sheets. Subsequently, clinicians offered consent forms and the opportunity to discuss the research further with the research team. Parents contacted the researchers to participate in the study at which time they were asked to verify their and their child's diagnosis and further consent to involvement. The study was approved by the research ethics committees of the community mental health service and Monash University.

\subsection{Participants}

There were 37 parents interviewed including 29 women and eight men with $59.5 \%(n=22)$ living in regional towns, the remainder living in semi-rural areas. While $24.3 \%(n=9)$ were employed, $45.9 \%(\mathrm{n}=17)$ were on a disability pension because of their mental illness. Parents were aged between 30 and 55 years with almost half between 36 to 45 years of age. Parents had a mix of diagnosis as did their children (see Table 1); most had comorbid anxiety and depression. All parents were, or had been, previous clients of adult mental health services. All children were active clients of CAMHS. Only $13.5 \%(n=5)$ of the parents indicated that they felt well supported within the community. All but one family reported extended family mental illness with many experiencing some level of domestic violence. From the original sample of 41 families, four parents withdrew from the study because of a deterioration in their mental health.

\subsection{Interviews}

Parents chose the venue for the discussion with the majority preferring to be interviewed in their own home. The lead author has over 20 years of extensive clinical experience working with children and families. Additional support and supervision were provided by a team of clinically skilled child psychologists. Development of the semi-structured interview questions was through a reference group of consumer advocates, child and adolescent clinicians and adult mental health clinicians. 
Table 1. Mental health \& G.P. recorded diagnosis of parent and child illnesses

\begin{tabular}{|c|c|c|c|c|}
\hline \multirow{2}{*}{ Mental IIlness } & \multicolumn{2}{|c|}{ Parent } & \multicolumn{2}{|c|}{ Child } \\
\hline & Number & Percentage & Number & Percentage \\
\hline ADHD and Anxiety & 0 & 0 & 3 & 8.1 \\
\hline Anxiety & 3 & 8.1 & 2 & 5.4 \\
\hline Anxiety and Depression & 25 & 67.6 & 13 & 35.1 \\
\hline Autism Spectrum Disorder & 0 & 0 & 2 & 5.4 \\
\hline Depression & 5 & 13.5 & 4 & 10.8 \\
\hline Early Psychosis & 0 & 0 & 2 & 5.4 \\
\hline Other ${ }^{*}$ & 0 & 0 & 11 & 29.7 \\
\hline Personality Disorder & 3 & 8.1 & 0 & 0 \\
\hline Schizophrenia & 1 & 2.7 & 0 & 0 \\
\hline Total & 37 & 100 & 37 & 100 \\
\hline
\end{tabular}

Note. ${ }^{*}$ Classified ICD10 - F98.9 (Unspecified behavioural and emotional disorders)/DSM 5 - Disruptive Mood Dysregulation Disorder

With the aims and objectives explained, and a written copy of the information sheet offered, parents consented to their family participation (interview information not included here). It was emphasised at the start and end that consent could be withdrawn at any time until the point transcripts were de-identified. Use of a Dictaphone voice recorder with subsequent transcription of the material was explained, one parent selected the use of written notes only. Interviews started and finished with a general conversation to help with the rapport building process. Connection was more easily established in the home setting and ensured an idiographic focus. Parents were offered several opportunities for clarification and to ask questions. Interview lengths varied with the most extended 90 minutes and the shortest 35 minutes. Some of the additional material was provided once the Dictaphone had been switched off.

The phenomenological approach used in the study sought to obtain an insight into how parents made sense of the bidirectional influences of mental illness in their family context. The principal aim being to explore in detail how these parents understood and conceptualised their experiences in terms of any bidirectional impacts between themselves and their child. To achieve this, a phenomenological approach was employed to help get close to the parent's experience of living with mental illness and also having a child with a mental illness. As described by Conrad ${ }^{[32]}$ we wanted to get an "insider's perspective". Initially 20 questions relating to the parent's experience were proffered in semi-structured interviews. The first three parents interviewed reported feeling stifled and stressed by the interview format and a review by the reference group led to a more open approach using the following general and non-leading prompts: (1) Please try and describe your experiences when you are unwell and when your child is unwell; (2) How, if at all, have you been supported as a family; and (3) Based on your experience how might other families be best supported?

This revised open inductive approach provided parents the opportunity to express their views and the researchers to hear those experiences. The open inductive approach also allowed for a bottom up understanding of each parent's situation. ${ }^{[33]}$ The thematic analysis applied full criteria of credibility, consistency, applicability and confirmability. ${ }^{[34]}$

\subsection{Data analysis}

Interviews were professionally transcribed, and text returned to the research team for thematic analysis. Utilising NVivo (for Mac, version 11.4.3) the transcribed material was reread several times to assist in capturing any patterns and to help the team get a sense of the phenomenon of the parent's experiences. Audio tapes were also reviewed to help with the empathic connections we sought in the parent's experiences. In the first part of the analysis responses were sorted into key common content areas. Secondly, an inductive thematic analysis was conducted in NVivo while ensuring we maintained the elements that described the parent's experience. It was important in this process to not lose the meaning behind the parent's understandings. Themes were deduced from the number of instances words and phrases occurred with ideas subsequently merged and catalogued. Finally, each of the team members coded responses independently, and codes were combined into common concepts. Uncertainties were resolved through discussion and agreement. With a range of phenomenological characteristics from the stories provided by the parents it was inevitable that many of the codes were not mutually exclusive. The precious data from parents provided both collective and individual themes as reported below in the results. Parents perspectives were taken as true and correct individual perceptions. 


\section{Results}

From analysis of the transcripts seven over arching themes emerged and these are presented below.

\subsection{Bidirectional impact of child-parent mental illness}

In this study all parents reporting an association between parent and child mental illnesses. Central to this theme was how a child's mental health impacted parents, irrespective of the classification of the parent's mental illness.

"Very difficult, it (anxiety) upsets the whole household, it goes from one child to the other, it is unsettling for everyone."

Mother depression: four daughters anxiety/depression.

The bidirectional impact was also illustrated by extreme child behaviour and the struggle of not letting their child's mental illness affect them.

"I sat up with him for three nights; I was tired I didn't know what to do because I didn't want to leave him in case he killed himself. But he was yelling and he got violent and angry - it's very scary because you don't know what to do... my anxiety went through the roof."

Mother anxiety/depression: son psychosis.

One parent described how she could not afford to fall apart for fear that everyone else (in the family) would do the same. Within this theme parents reported concern about their child's mental illness, worry about their own health, and anxiety for the future. The concept of "holding it together" was important for parents who sought to suppress their own mental illness to help them manage their child's mental illness. In addition to bidirectional influences of anxiety, mood and frustration, parents reported anger as they sought to redirect their emotions when their child was unwell. Redirection and staying calm and relaxed was more difficult when they too were unwell. Parent's struggled with fear of being "tipped over the edge" by their child's mental illness. Observing mental illness in their child added to parental stress: as did the reported feelings of not being believed when they first voiced concerns about their child. Parents disclosed frustration and confusion before their child was diagnosed believing this was because of their own mental illness. They described this period of uncertainty as causing an aggravation of their mental illness.

\subsection{Socio-economic issues for families}

Family violence, finances, work, transport and accommodation were all issues for some of the families in this study. Family violence from ex-partners and family violence between parents and children were reported by a large minority of families and were major contributors to both parent and child mental illness.

"She was really scared of her father and was making herself sick in order to be picked up from school and not go to her dads and all sorts of things and then that just made me even more anxious."

Mother personality disorder: three daughters anxiety/depression.

Finances were a major concern with one mother reporting:

"Finances can be such a burden, you know when you are unwell like my anxiety when I couldn't get out of the house and then I just got more anxious worrying how he would get food and stuff."

Mother agoraphobia: daughter anxiety.

For most parents going to work was an impossibility, even when mentally well. Needing "to deal" with their child was a significant barrier to being able to work. Difficulties getting to appointments was raised by half these parents. Predominantly getting to CAMHS appointments was a challenge though for some attending adult mental health services was as much a challenge. Catching multiple buses and juggling pickup of other children was a major barrier to obtaining intervention. Accommodation impacts included: houses too small, being isolated, community problems, and landlords blaming mental illness for housing issues. While a problem for some, others saw home as a sanctuary - a safe place, to escape pressures in society and the stigma they perceived they had experienced because of mental illness.

\subsection{School issues}

School was highlighted as a major difficulty for most of the parents with the greatest concerns about bullying experienced by their child and how this resulted in a knock-on impact on their mental health. For most of the parents it was a struggle persuading their children to attend school and commonly this resulted from their child wanting to care for them. Additional stress for parents was the tendency of schools to call when children presented with even minor emotional difficulties.

"It is stressful when the school has trouble dealing... when they struggle, the first person they would call is me, which is hard for me."

Father anxiety/depression: daughter depression.

Schools frequently calling parents added to parental anxiety. These calls resulted in lowered parental mood because of uncertainty and insecurity on how they might manage their child's mental illness. The issue of lack of training for teachers and limited welfare support in schools was a major concern for parents. However, one parent highlighted 
good school support as occurring in a few schools though she noted this support could easily be disrupted.

"School was my support that was giving me time through the day, but ... at the same time, you never knew when they were going to ring you up and say 'Look come and get him'”.

Mother anxiety/depression: autistic son with anxiety.

\subsection{Parenting with a mental illness}

Most parents reported "triggering" others in the family and how their own mental illness changed their parenting behaviour and their responses as a parent. Feelings of being an inadequate parent when unwell was described by a majority of the parents.

"That's been really upsetting for him and really triggering his anxiety so... it's hard for any parent to deal with but if you already had anxiety yourself, and then your kid's anxiety flares up, it's really very difficult."

Father anxiety: two children anxiety.

They described their mental illness impacting on what they could or could not do and how inadequate they sometimes felt as a parent. Many parents described behaving irrationally when mentally unwell, but they recognized their children just accepted this as "the way things are".

Hospitalization, or being "taken away" by mental health services, was a major issue for over half of the parents, particularly not knowing what happened to children. Lack of reassurance or information was described as adding to increasing dysregulation which in turn prevented them from successfully expressing their concerns. For some they felt this made them seem more unwell.

"I'm scared for him, you know because I, like many years ago I was scared for myself, I was crying out for help but I was overdosing and I was crying out for help myself."

Mother personality disorder: child depression.

Socialization issues were described as exacerbated by parentchild mental illness, as was guilt over mental illness "consuming" both parents and children.

All the fathers reported feeling "out of control" when unwell and struggling with frustration and anger issues which they felt unable to control. These fathers described inner guilt over their response to their child's mental illness. Associated to anger all parents reported the issue of stigma, in relation to mental illness, as a substantial burden for them. Parents described stigma as widely occurring in different contexts: in interactions with others; in relation to support services in the community; family; and schools. A mother with a terminal illness felt well supported for her physical issues but stigmatized because of her mental illness.

"I just feel like, why do they make me feel so bad-I already feel shame, why do you keep rubbing it in with stigma, you know what I mean?"

Mother with cancer, anxiety/depression: son anxiety.

Parents highlighted the major challenges of managing their own mental illness and supporting their child with mental illness. They often blamed themselves for a number of issues including: their child's mental illness; child behaviour difficulties; failing to prevent bidirectional influence; and feeling powerless to provide "mental stability" to prevent their child becoming unwell. All found parenting a child with a mental illness stressful and highlighted how this had a considerable impact on their own mental health. The consequence was an effect on parental self-esteem and confidence in their parenting abilities.

“... my kids can be a big stress on me that often sets me off so no matter how hard I try the kids often cop it."

Father depression/psychosis: two children anxiety/depression.

\subsection{Useful family strategies}

Parents identified strategies specific to the challenges of bidirectional parent-child mental illness. These included the following child, parent and family focused strategies.

\subsubsection{Child}

Parents described reducing the bidirectional influence of mental illness through walking away, usually with children or parents going to their room.

"They sort of go off and stay by them self in their rooms."

Mother depression/anxiety: four children anxiety.

Half of the parents found this useful whilst the other half found it frustrating wanting to talk things over. All parents recognized this strategy as an effective way to de-escalate situations between family members.

\subsubsection{Parent}

One strategy used by parents was utilizing the home as a safe sanctuary and a place to keep stigma, and the outside world, at bay.

"... making an effort to give him more attention and the fact he was in our room... making a deliberate effort too, because I realised it was an issue."

Mother anxiety/obsessive-compulsive disorder (OCD): daughter anxiety. 
These parents described routine as the way to manage mental illness in the family. Staying attuned to their child's mental health and trying to suppress their own mental illness was also important. For most parents, when first having a child, there was an initial anxiety over anticipated child mental illness. As children became older a determination developed that provided them a level of aptitude to inhibit their mental illness to support their child. Importantly all these parents sought, often inadequately, to try and protect their child from distress about parental mental illness. Whilst infrequently successful they felt reassured they had made the effort. Despite mental illness parents described being available for children was an important aspect for protecting them.

A common strategy used by parents was distance or using distraction. Giving time to get their mental health "back on track" was a frequent approach. Pets were identified by many as a great calmer for both themselves and their child. Other parents used the internet to learn parenting strategies though, most preferred strategies from family and friends.

\subsubsection{Family strategies}

Focusing on agencies, particularly schools, helped redirect stress giving a sense of control. Half appreciated that their actions were seen by others as reflections of their mental illness. Sharing problems was important for $73 \%(n=27)$ of parents.

“.. our family just talk about problems: it's a problem session but it really makes my son happy to know he's not the only one going through this emotional roller coaster. Family time is very special which I actually fit in every day."

Mother anxiety/depression: son anxiety/depression.

However, only a small number of parents had whole family strategies involving family time and conversation where everyone would talk about their emotions and feelings.

\subsection{Sources of support}

This was the second area to generate the greatest response from parents. Difficulties with schools, mentioned above, and family doctors were often reported as a problem. The majority of parents believed their mental illness clouded responses from professionals when they raised concerns about their children. Other key support issues included: the brevity of interventions; substantial gaps between appointments; referrals being made to specialists some distance away, in the city; prohibitively costly supports, such as psychiatric input; and being advised to use the internet which added to confusion and anxiety for parents.

All but two highlighted the need for external family support suggesting support should start as early as possible with

Published by Sciedu Press agencies needing to recognize that parenting with a mental illness has unique challenges.

"I think that it's really important that doctors and people that are in those sorts of jobs listen more and understand more and consider mental health more in kids because I feel like that was not even considered for my daughter."

Mother OCD: daughter anxiety.

All the parents reported difficulty in finding services that were understanding of the bidirectional impact of mental illness. Providing understandable and accessible information to parents, to improve parenting knowledge and skills, was thought vital for helping these parents. Parents also highlighted the importance of raising awareness of mental illness, including within schools. Overwhelmingly parents felt organizations and agencies being cognizant of the nature of bidirectional mental illness in families was fundamental. Some of the parents would have liked respite opportunities as well as groups for children focusing on the bidirectional impacts of mental illness.

\subsection{Intergenerational mental illness}

Parents spoke of transgenerational mental illness best described by one parent:

"I have this child, and I give her anxiety through this, you know, whole transgenerational thing, I can see from my father's own mother, you know, very difficult. ... So, it was like I could see that (mental illness) coming... Mental illness is toxic, weighs you down, using so much energy supressing. And then when you do behave strangely, you're not quite sure why you're behaving strangely, and it's because of those split-off thoughts. It's just you being dysregulated, you're making your child dysregulated and you got it from your parents."

Mother OCD: daughter OCD/anxiety.

All but one family reported other family members, such as a grandmother or grandfather, with a mental illness.

\section{Discussion}

This article contributes to the literature on mental illness in families in two significant ways. Firstly, some themes generated by parents reiterate findings from current published research. However, these established themes are from a very unidirectional rather than bidirectional viewpoint. Earlier studies have primarily considered viewpoints of children living with a parent with a mental illness. This study expands the thinking as it looks at bidirectional and intergenerational impacts of mental illness. Secondly, in examining themes where both a parent and a child have a mental illness, we 
have opened a new and previously neglected discourse. From the voices of these parents' the very specific challenges faced in families where both a parent and a child have a mental illness have been emphasized.

Parent interviews reaffirmed previously well-documented difficulties relating to school, stigma, community and supports. Social difficulties, highlighted earlier, are in line with Platt et al. ${ }^{[35]}$ who found events, such as school problems, may increase parental stress and child anxiety. Bibou-Nakou ${ }^{[36]}$ and Reupert and Maybery ${ }^{[14]}$ have suggested school staff may not have training or knowledge on what to do in relation to mental illness, an issue identified here. Strategies for families might usefully focus on providing schools psycho-education on matters relating to bidirectional impacts of mental illness. Supporting teachers in developing positive relationships and improving perceptions of families would also reduce stress. Consistent with Corrigan et al. ${ }^{[37]}$ the issue of stigma impacting parents was an enduring problem. In the study by Hasson-Ohayona et al. ${ }^{[38]}$ stigma was found to produce a sense of shame in extended family members because of negative views about mental illness. These negative views were equally discovered in the wider community. For some of the parents' in this study social isolation was preferable to experiencing the stigma they felt in relation to their and their child's mental illness.

In this study historical family violence and an emotional intensity between parents and children was a common experience. We found other socioeconomic issues including finances, poor or inadequate accommodation, and transport issues were predominant concerns for parents. Factors such as these are well documented in the literature. ${ }^{[39-42]}$ In this research however, parents perceived having two people with mental illness in the family compounded socioeconomic and other issues.

Importantly this research adds to current literature with the following new themes emerging from parent interviews: general bidirectional impacts between parent and child mental illness; élite impacts of bidirectional influences; and specific strategies related to bidirectional effects. As interviewees were parents, where they and their child both had mental health problems, predictably the bidirectional impact of mental illness emanated as a key theme. Irrespective of diagnosis, all parents described a psychosocial association between parent and child mental illness. Critically parents described how child mental health problems impacted their own mental illness. They also explained that the mix of their own and their child's mental illness had a profound effect on how they parented. Parents reported how the sometimes-extreme behavior of children would upset and unsettle everyone in the family. An ongoing struggle existed for parents in trying not to let the child's illness affect their illness which in itself had an influence on overall levels of family stress. This dilemma was typified by one parent suggesting:

"If my anxiety or depression is playing up I surely react differently to the way she is behaving, that is a huge part, my mental health, the way I feel about myself, affects greatly how I parent."

Father Anxiety/medical issue: daughter anxiety/depression.

In this interplay the parents indicated the importance of subduing their own mental health concerns for the benefit of their parenting and children. This finding extends the previous work in this area (e.g. ${ }^{[43-46]}$ ) including that related to the impact on parenting. ${ }^{[47,48]}$ This research supports the theoretical approach of the Falkov ${ }^{[16]}$ Crossing Bridges Family Model. The findings put 'flesh on the bones' of the Falkov model which describes the "... interplay between any child's response to parental symptoms and the consequent effects (emotional and behavioral adaptations) on parents, siblings and others in the family" (Falkov, p.118). ${ }^{[16]} \mathrm{He}$ argues for the importance of the parent child dyad in affecting, even intensifying, a deterioration in mental health. His family model emphasizes "how risk and resilience may be transmitted through generations." (Falkov, p.40). ${ }^{[16]}$ The interplay between the mental illness of parents and children was a significant aspect of this study. Intergenerational transmission of mental illness was an important feature evident in this study with almost all participants indicating transgenerational mental health problems within their families.

Parents keenly described, in-depth, the interplay between their mental illness and family functioning. This was important as they disclosed struggling with guilt and worry over any influences they might have on their child's mental illness. Universally, deterioration in parental mental health triggered emotional responses in other family members. These emotional responses were displayed through worsening mental health and increased negative behaviors. Parents described "blocking out" their own behavior's when unwell. These reports by parents reinforced our proposition of a bidirectional impact of mental illness.

The research revealed that parents being hospitalized impacted in two discreet ways; firstly, by removing parenting influences in the family, and secondly impacting on family socialization through increased stigma. From both the children and parent's perspectives, parental hospitalization had a major impact on families. ${ }^{[13]}$ In the Swedish study by Östmann and Kjellin ${ }^{[49]}$ relatives of patients in a psychiatric unit reported patients' mental illness impacted on relation- 
ships and their relatives mental health. In this study parents' descriptions of children being overlooked, with what they felt was little regard by professionals of any emotional impacts, highlights potential gaps in service delivery. Inevitably a stressful situation was doubtless compounded where the child also had a mental illness.

Parents outlined fundamental strength-based strategies for the management of parent-child mental illness (e.g. getting away; building a home sanctuary). Being attuned to each other and establishing and maintaining strong routines was also important. These ideas invite similarities to traumainformed models of care recognizing stability, routines and trust as helping individuals. ${ }^{[50]}$ Whilst not new such ideas suggest formal inclusion of these interventions in discussions with families where there is parent-child mental illness.

Parents described two areas they felt were neglected by mental health services. They felt unsupported in adjusting to living with a child with mental illness and they felt their treatment was managed in isolation with poor, or non-existent, family approaches. Parents described inadequate help managing the "grief" of having a child with a mental illness. None received reassurance or guidance in relation to their fears of bidirectional influences. Corrigan and Miller ${ }^{[51]}$ highlight parents as frequently stigmatized for their child's mental illness. Whilst Saunders, ${ }^{[52]}$ in the study of 37 parents, found stress common for all family members. Importantly parents did not feel specialist child mental health services took any account of parental mental illness when supporting children. It is unclear why such gaps exist, but two possibilities need consideration. Firstly, a great deal is written about the impact of parental mental illness on children only a few references $^{[15,53,54]}$ relate to the impact of children's mental illness on parents. Secondly a focus on person centered care and individual recovery appears to reinforce the individual over the communal family. As expounded by Gask and Coventry ${ }^{[55]}$ there needs to be a move from "patient-centeredness" (p.142) to family and community. Focusing on the parent as an individual, rather than as a parent in a family, further impacts on their mental health. Such an emphasis reinforces a sense of uncertainty insecurity and feelings of inadequacy as a parent. Effectively supporting family units, going beyond the "patient", is indicated as an approach for improving parent's mental health and aiding whole family recovery. Kaplan and Racussen $^{[56]}$ determined intervention should support service users to take ownership and control of managing their recovery. For these parents that ownership and control is around being heard, with services mutually embracing support for both the parent and the child. Falkov ${ }^{[16]}$ describes how services need to be connected with, and responsive to, people with mental illness to enable effective intervention. Six years

Published by Sciedu Press on from Falkov the parents in this study reported little change to the individual approach.

\section{Study limitations and strengths}

Families were recruited through clinician referral, a methodology reliant on clinician interest and potentially a predisposed type of family. Similarly, the parent's interest in taking part may have impacted on the rationale for involvement. The level of parental acuity and state of mental health may have been an additional dimension which might have influenced responses.

It was notable while interviews were conducted in a very informal friendly manner, to support parent engagement, this approach resulted in a brutally honest and open discourse. The difficulty for these parents of acknowledging the challenges of being a parent with a mental illness cannot be underestimated. Honesty born out of frustration with services and elements of their own mental illness might be considered a limitation but can also be considered a strength. Equally, despite being initially guarded a parent with paranoid schizophrenia was determined to have her voice heard despite at times feeling mentally overwhelmed. This desire to have their voice heard was evident with all the parents. Two parents, who have subsequently died because of their physical health problems, viewed the study as a lasting legacy in raising awareness of bidirectional influences of mental illness.

Despite mostly negative experiences the parent's narrative contained a number of positive characteristics. Concepts of love of their child and everyone doing their best to help each other, as well as families pulling together, all important aspects which might also be considered as limiting factors.

\section{Conclusions}

People with a mental illness have a difficult journey when they become parents. In addition to managing their mental illness they have challenges of stigma and denunciation. There is little if any information given on influences of parental mental illness on children. Bidirectional impacts of mental illness are typically not considered by mental health services.

With limited support and imperfect intervention these parents have developed personal strategies to manage. They highlight a critical need to address how parents with mental illness are supported when they have children of their own. Our investigation has revealed gaps in provision for these families with clinicians needing to take account of bidirectional influences. Reassurance for parents in relation to their child can help alleviate stress. There needs to be greater emphasis on training clinicians in the understanding 
of bidirectional impacts of mental illness. As highlighted by Falkov $^{[16]}$ clinicians being able to support parents in managing emotional impacts of mental illness is fundamental. Challenging stigma, engagement, and early intervention are important to these parents. Providing skills in understanding early years attachment and working with children's emotions are key skills parents need. More research is needed into the bidirectional impact of mental illness looking at both positive and negative factors. With limited research focusing on Parents of Children with Mental Illness (PoCMI) this is an area needing further investigation.

\section{CONFLicts OF InTEREST Disclosure}

The authors declare they have no conflicts of interest.

\section{REFERENCES}

[1] Leijdesdorff S, Van DK, Popma A, et al. Prevalence of psychopathology in children of parents with mental illness and/or addiction: an up to date narrative review. Curr Opin Psychiatry. 2017; 30(4): 312 317. PMid: 28441171 . https ://doi.org/10.1097/YCO. 000000 0000000341

[2] Gottesman II. Schizophrenia genesis: the origins of madness. New York: Freeman; 1991.

[3] Walker EF, Diforio D. Schizophrenia: a neural diathesis-stress model. Psychological Review. 1997; 104(4): 667-685. https ://doi.org/ 10.1037/0033-295X.104.4.667

[4] Halmøy A, Johansson S, Winge I, et al. Attentiondeficit/hyperactivity disorder symptoms in offspring of mothers with impaired serotonin production. Archives of General Psychiatry. 2010; 67(10): 1033. PMid: 20921119. https://doi.org/10.1001/archgenpsychiatry.2010.124

[5] Badcock C, Crespi B. Battle of the sexes may set the brain. Nature. 2008; 454(7208): 1054-1055. PMid: 18756240. https://doi.or $\mathrm{g} / 10.1038 / 4541054 \mathrm{a}$

[6] van Santvoort F, Hosman CM, Janssens JM, et al. The Impact of Various Parental Mental Disorders on Children's Diagnoses: A Systematic Review. Clinical Child \& Family Psychology Review. 2015; 18(4): 1-19. PMid: 26445808. https://doi .org/10.1007/s105 67-015-0191-9

[7] Maybery D, Reupert AE. The number of parents who are patients attending adult psychiatric services. Current Opinion in Psychiatry. 2018; 31(4): 358-362. PMid: 29847344. https ://doi .org/10.1 097/YCD.0000000000000427

[8] Göpfert M, Webster J, Seeman MV. Parental psychiatric disorder: Distressed parents and their families. Cambridge: Cambridge University Press; 2004. https://doi.org/10.1017/CB097805115438 38

[9] Maybery D, Reupert A. Parental mental illness: A review of barriers and issues for working with families and children. Journal of Psychiatric and Mental Health Nursing. 2009; 16: 784-791. PMid: 19824972. https://doi.org/10.1111/j.1365-2850.2009.0 $1456 . x$

[10] Gladstone BM, Boydell KP. Recasting research into children's experiences of parental mental illness: beyond risk and resilience. Social Science \& Medicine. 2006; 62(10): 2540-2550. PMid: 16316714. https://doi.org/10.1016/j.socscimed.2005.10.038

[11] Cowling V. Children of Parents with Mental Illness. A. C. f. E. Research, ed., Melbourne. 1999.

[12] Rutter M, Silberg J, O'Connor T, et al. Genetics and Child Psychiatry: II Empirical Research Findings. Journal of Child Psychology \& Psychiatry. 2010; 40(1): 19-55. https://doi.org/10.1111/14 69-7610.00423

[13] Maybery DJ, Ling L, Szakacs E, et al. Children of a parent with a mental illness: perspectives on need. Australian e-Journal for the Advancement of Mental Health. 2005; 4(2): 1-11. https: //doi.org/10.5172/jamh.4.2.78

[14] Reupert A, Maybery D. Families affected by parental mental illness: a multiperspective account of issues and interventions. American Journal of Orthopsychiatry. 2007; 77(3): 362-369. PMid: 17696664 https://doi.org/10.1037/0002-9432.77.3.362

[15] Gunlicks ML, Weissman MM. Change in child psychopathology with improvement in parental depression: a systematic review. J Am Acad Child Adolesc Psychiatry. 2009; 47(4): 379-389. PMid: 18388766. https://doi .org/10.1097/CHI .0b013e3181640805

[16] Falkov A. The Family Model Handbook: An integrated approach to supporting mentally ill parents and their children. Hove: Pavillion Publishing; 2012. PMid: 23054375.

[17] Vondrova D, Kapsdorfer D, Argalasova L, et al. The impact of selected environmental, behavioral and psychosocial factors on schoolchildren's somatic and mental health. Reviews on Environmental Health. 2017; 32(1): 189-192. https://doi .org/10.151 5/reveh-2016-0034

[18] Garbarski D, Witt WP. Child Health, Maternal Marital and Socioeconomic Factors, and Maternal Health. J Fam Issues. 2012; 34(4): 484-509. PMid: 23788824. https ://doi .org/10.1177/019251 $3 \times 12443052$

[19] Hayes SA, Watson SL. The impact of parenting stress: A metaanalysis of studies comparing the experiences of parenting stress in parents of children with and without autism spectrum disorder. Journal of Autism and Developmental Disorder. 2013; 43(3): 629-642. PMid: 22790429. https://doi.org/10.1007/s10803-012-1 $604-y$

[20] Kuusikko-Gauffin S, Pollock-Wurman R, Mattila ML, et al. Social Anxiety in Parents of High-Functioning Children with Autism and Asperger Syndrome. Journal of Autism \& Developmental Disorders. 2013; 43(3): 521-529. PMid: 22733299. https ://doi.org/10.1 007/s10803-012-1581-1

[21] Manuel J, Naughton MJ, Balkrishnan R, et al. Stress and Adaptation in Mothers of Children With Cerebral Palsy. Journal of Pediatric Psychology. 2003; 28(3): 197-201. PMid: 12654945. https://doi.org/10.1093/jpepsy/jsg007

[22] Guethmundsson OO, Tómasson K. Quality of life and mental health of parents of children with mental health problems. Nordisk Psykiatrisk Medlemsblad. 2009; 56(6): 413-417. PMid: 12495535. https://doi.org/10.1080/08039480260389325

[23] Busch SH, Barry CL. Mental Health Disorders In Childhood: Assessing The Burden On Families. Health Affairs. 2007; 26(4): 10881095. PMid: 17630451. https://doi.org/10.1377/hlthaff. 26.4 .1088

[24] Mensah FK, Kiernan KE. Parents' mental health and children's cognitive and social development. Social Psychiatry \& Psychiatric Epidemiology. 2010; 45(11): 1023-1035. PMid: 19823757. https://doi.org/10.1007/s00127-009-0137-y 
[25] Radke-Yarrow M, Klimes-Dougan B. Parental depression and offspring disorders: A developmental perspective. In Children of Depressed Parents: Mechanisms of Risk and Implications for Treatment. I. G. S. Goodman, ed. Washington: American Psychological Press; 2002. 155-173 p. https://doi.org/10.1037/10449-006

[26] Jessop ME, Bondt ND. A consultation service for Adult Mental Health Service clients who are parents and their families. Advances in Mental Health. 2012; 10(2): 149-156. https://doi.org/10.5 172/jamh.2011.10.2.149

[27] Gatsou L, Yates S, Hussain S, et al. Parental mental illness: incidence, assessment and practice. Mental Health Practice. 2016; 19(5): 25-27. https://doi.org/10.7748/mhp.19.5.25.s18

[28] Van Veen SC, Batelaan NM, Wesseldijkj LW, et al. Psychiatric disorders within families: an integrated approach through the family clinic. Tijdschrift Voor Psychiatrie. 2016; 58(2): 95-105. PMid: 26881342.

[29] Naughton MFA, Maybery D, Goodyear M. Prevalence of mental illness within families in a regional child-focused mental health service. International Journal of Mental Health Nursing. 2017; 901-910. PMid: 28929573.

[30] Baker L, Lees R. Parental Mental Illness and Coping: An Exploratory Survey. Canadian Journal of Family \& Youth. 2014; 6(1): 115-133.

[31] Gladstone BM. "All in the Same Boat": An Analysis of a Support Group for Children of Parents with Mental Illness. Dalla Lana School of Public Health, University of Toronto, Toronto; 2010.

[32] HConrad P. The experience of illness:recent and new directions. Research in the Sociology of Health Care. 1987; 6: 1-31.

[33] Bowman G, MacKay RB, Masrani S, et al. Storytelling and the scenario process: Understanding success and failure: Understanding success and failure. Technological Forecasting and Social Change. 2013; 80: 735-748.

[34] Hasson F, Keeney S, Mckenna H. Research guidelines for the Delphi survey technique. Journal of Advanced Nursing. 2010; 32(4): 1008-1015.

[35] Platt R, Williams SR, Ginsburg GS. Stressful Life Events and Child Anxiety: Examining Parent and Child Mediators. Child Psychiatry \& Human Development. 2016; 47(1): 23-34. PMid: 25772523. https://doi.org/10.1007/s10578-015-0540-4

[36] Bibou-Nakou I. Helping teachers to help children living with a mentally ill parent. School Psychology International. 2004; 25(1): 42-58. https://doi.org/10.1177/0143034304041502

[37] Corrigan PW, Watson AC, Barr L. The self-stigma of mental illness: Implications for self-esteem and self-efficacy. Journal of Social \& Clinical Psychology. 2006; 25(8): 875-884. https ://doi .org/10 $.1521 /$ jscp. 2006.25.8.875

[38] Hasson-Ohayon I, Levy I, Kravetz S, et al. Insight into mental illness, self-stigma, and the family burden of parents of persons with a severe mental illness. Comprehensive Psychiatry. 2011; 52(1): 7580. PMid: 21220068 . https://doi .org/10.1016/j.comppsyc h. 2010.04 .008

[39] Molarius A, Berglund K, Eriksson C, et al. Mental health symptoms in relation to socio-economic conditions and lifestyle factors - a population-based study in Sweden. BMC Public Health. 2009; 9(1): 302. PMid: 19695085. https://doi.org/10.1186/1471 $-2458-9-302$

[40] Rutherford C, Hill J, Sharp H, et al. OP21 Assessing the impact of childhood socio-economic conditions on child mental health: findings from the Wirral child health and development study. Journal of Epidemiology and Community Health. 2017; 71(1): 11.

[41] Mohammad ET, Shapiro ER, Wainwright LD, et al. Impacts of Family and Community Violence Exposure on Child Coping and Mental Health. Journal of Abnormal Child Psychology. 2015; 43(2): 203-
215. PMid: 25084981. https://doi.org/10.1007/s10802-0 14-9889-2

[42] Simon JD, Brooks D. Identifying families with complex needs after an initial child abuse investigation: A comparison of demographics and needs related to domestic violence, mental health, and substance use. Child Abuse Negl. 2017; 67: 294-304. PMid: 28327415. https://doi.org/10.1016/j.chiabu.2017.03.001

[43] Pettit GS, Arsiwalla DD. Commentary on Special Section on "Bidirectional Parent - Child Relationships": The Continuing Evolution of Dynamic, Transactional Models of Parenting and Youth Behaviour Problems. Journal of Abnormal Child Psychology. 2008; 36: 711718.

[44] Gross HE, Shaw DS, Dishion TJ. Reciprocal Models of Child Behaviour and Depressive Symptoms in Mothers and Fathers in a Sample of Children at Risk for Early Conduct Problems. Journal of Family Psychology. 2008; 22(5): 742-751.

[45] Cooklin AR, Dinh H, Strazdins L, et al. Change and stability in workfamily conflict and mothers' and fathers' mental health: Longtitudinal evidence from an Australian cohort. Social Science and Medicine. 2016; 151: 24-34.

[46] Rohde N, Tang KK, Osberg L, et al. The effect of economic insecurity on mental health: Recent evidence from Australian panel data. Social Science and Medicine. 2016; 151: 250-258.

[47] Mazur E, Mickle CL. Online Discourse of the Stressors of Parenting Children with Mental Health Disorders. Journal of Child and Family Studies. 2018; 27: 569-579.

[48] Achtergarde S, Postert C, Wessing IR, et al. Parenting and Child Mental Health: Influences of Parent Personality, Child Temperament, and Their Interaction. The Family Journal: Counseling and Therapy for Couples and Families. 2015; 23(2): 167-179.

[49] Ostman M, Kjellin L. Stigma by association: psychological factors in relatives of people with mental illness. British Journal of Psychiatry the Journal of Mental Science. 2002; 181(6): 494. https://doi.org/10.1192/bjp.181.6.494

[50] Ko SJ, Ford JD, Kassam-Adams N, et al. Creating Trauma-Informed Systems: Child Welfare, Education, First Responders, Health Care, Juvenile Justice. Professional Psychology Research \& Practice. 2008; 39(4): 396-404. https://doi.org/10.1037/0735-7028.39.4 .396

[51] Corrigan PW, Miller FE. Shame, blame, and contamination: A review of the impact of mental illness stigma on family members. Journal of Mental Health. 2004; 13(6): 537-548. https: //doi.org/10.1080/09638230400017004

[52] Saunders JC. Families Living with Severe Mental Illness: A Literature Review. Issues in Mental Health Nursing. 2003; 24(2): 175198. PMid: 12554427 . https ://doi.org/10.1080/0161284030 5301

[53] Gladstone BM, Boydell KM, Seeman MV, et al. Children's experiences of parental mental illness: a literature review. Early Intervention in Psychiatry. 2011; 5(4): 271-289. PMid: 21883973. https://doi.org/10.1111/j.1751-7893.2011.00287.x

[54] Maybery D, Reupert A, Patrick K. Vic Health research report on children at risk in families affected by parental mental illness. VicHealth Research Report. 2005.

[55] Gask L, Coventry P. Person-centred mental health care: the challenge of implementation. Epidemiology \& Psychiatric Sciences. 2012; 21(2): 139-144. PMid: 22789160. https://doi.org/10.1017/ S2045796012000078

[56] Kaplan T, Racussen L. A crisis recovery model for adolescents with severe mental health problems. Clinical Child Psychology \& Psychiatry. 2012; 18(2): 246-59. PMid: 23060601. https ://doi .org/10 $.1177 / 1359104512449320$ 